Article

\title{
Sunbed Use Prevalence and Associated Skin Health Habits: Results of a Representative, Population-Based Survey among Austrian Residents
}

\author{
Daniela Haluza ${ }^{1, *}$, Stana Simic ${ }^{2}$ and Hanns Moshammer ${ }^{1}$ \\ 1 Institute of Environmental Health, Center for Public Health, Medical University of Vienna, \\ Kinderspitalgasse 15, Vienna A-1090, Austria; hanns.moshammer@meduniwien.ac.at \\ 2 Institute of Meteorology, University of Natural Resources and Life Sciences, Vienna, Peter-Jordan-Straße 82, \\ Vienna A-1190, Austria; stana.simic@boku.ac.at \\ * Correspondence: daniela.haluza@meduniwien.ac.at; Tel.: +43-1-401-603-4933; Fax: +43-1-401-609-34903 \\ Academic Editor: Anthony R. Mawson \\ Received: 26 January 2016; Accepted: 15 February 2016; Published: 19 February 2016
}

\begin{abstract}
Recreational sunbed use accounts for the main non-solar source of exposure to ultraviolet radiation in fair-skinned Western populations. Indoor tanning is associated with increased risks for acute and chronic dermatological diseases. The current community-based study assessed the one-year prevalence of sunbed use and associated skin health habits among a representative, gender-balanced sample of 1500 Austrian citizens. Overall one-year prevalence of sunbed use was 8.9\% (95\% confidence interval (CI) $7.5 \%-10.4 \%$ ), with slightly higher prevalence in females $(9.2 \%, 95 \%$ CI $7.3 \%-11.2 \%)$ compared to males $(8.6 \%, 95 \% \mathrm{CI} 6.7 \%-10.6 \%)$. Factors predicting sunbed use were younger age (by trend decreasing with older age), place of living, smoking, skin type (by trend increasing with darker skin), sun exposure, motives to tan, and use of UV-free tanning products. Despite media campaigns on the harmful effects of excessive sunlight and sunbed exposure, we found a high prevalence of self-reported sunbed use among Austrian citizens. From a Public (Skin) Health perspective, the current research extends the understanding of prevailing leisure time skin health habits in adding data on prevalence of sunbed use in the general Austrian population.
\end{abstract}

Keywords: public health; preventive medicine; sun exposure; photo-protection; gender

\section{Introduction}

From an evolutionary perspective, fair skin is seen as a selection advantage in regions with low solar intensity by preventing vitamin D deficiency, thus, increasing longevity and fertility as well as preventing autoimmune diseases and cancer development [1,2]. Exposure to natural and artificial ultraviolet radiation (UVR) initiates the physiological process of skin tanning, which is associated with epidermal cells damage [3]. A growing body of scientific evidence argues for the carcinogenic properties of indoor exposure to ultraviolet radiation [4-9]. However, the popularity of indoor tanning as recreational pastimes is hardly on the wane in Western countries with mainly fair-skinned populations [10-12]. Wehner et al. estimated that over 400,000 non-melanoma and 10,000 melanoma cases each year are attributable to sunbed use in the U.S., Europe, and Australia [13].

Worldwide, several countries implemented more stringent policies and programs to mitigate sunbed use, increase customer stewardship, raise awareness, and provoke action by government and industry [14,15]. Recently, the number of countries restricting underage youth access to indoor tanning facilities increased from two countries (Brazil, France) in 2003 to eleven countries in 2011, now including Austria, Belgium, Germany, Portugal, Spain, and the U.K. in Europe, and parts of Canada, the U.S, and Australia [15]. 
Limiting UVR exposure and increasing sun protection could reduce skin cancer incidence rates and associated healthcare costs $[16,17]$. Awareness campaigns as an important tool for skin cancer prevention influence tanning attitudes and educate the public about appropriate photo-protection [18,19]. The effect of these campaigns in diminishing recreational sunbed use, potentially due to vast media and public policy attention, seems encouraging [20,21].

Based on the broader concept of Public Health, the umbrella term Public (Skin) Health refers to skin health-related activities aimed at lowering incidence rates of photo-induced skin manifestations [22-27]. By encouraging individuals to adopt skin health-sensitive behaviors, Public (Skin) Health has practical implications for community-based skin health promotion. Focusing on potential risks accompanied with recreational exposure to solar and artificial UVR, the respective research activities define risk groups as target for according educative campaigns and public policies. In this context, Bock et al. identified a need for studies examining behavioral patterns related to sunbed use on a national level to develop successful skin health promotion strategies [21].

Similar to other countries, Austrian melanoma incidence rates (1983: 4.8; 2012: 12.3/100,000) and mortality rates (1983: 1.9, 2012: 2.2/100,000) have constantly increased over the last decades [28,29]. Despite these rising skin cancer rates, little is known about the national prevalence of sunbed use and the associated skin health burden in Austria as a potential lifestyle factor influencing the individual skin cancer risk. To close this knowledge gap, we conducted the population-based UV Skin Risk survey to assess prevailing intentional tanning behaviors including sunbed exposure as well as sunless tanning product use. Thus, this article specifically analyzed socio-demographic characteristics, knowledge, and attitudes of sunbed users in comparison to non-users.

\section{Methods}

\subsection{Study Population}

The current study presents data on prevailing indoor and outdoor tanning practices in relation to skin health knowledge, attitudes, and motives collected by the cross-sectional, population-based UVSkinRisk survey. This study was performed in accordance with the ethical standards of the Declaration of Helsinki and was approved by the local ethics committee of the Medical University of Vienna. Further methodological details are given elsewhere $[25-27,29,30]$. In short, we contracted the independent, Vienna-based market research company Triconsult to conduct the questionnaire-based telephone survey in August 2011. As a third party, Triconsult also ensured quality control and respondents' anonymity. The study sample represented the target population of the German-speaking general Austrian population according to the national 2011 census data regarding age, population of federal states, and population size of place of residence [31,32]. We used stratified random sampling on the basis of 20,000 telephone numbers from the official national telephone directory list. About 11,100 individuals were contacted to finally reach the pre-set number of 1500 Austrian male and female survey participants representing the general population. Verbal consent was obtained from all respondents prior to the telephone interview. Participation in the questionnaire-based telephone interview of approximately 10-12 $\mathrm{min}$ in length was voluntarily and anonymous.

\subsection{Survey Questionnaire}

The questionnaire collected socio-demographic data including age, gender, place of residence, city size, highest attained education, and occupational situation as well as personal status. All Austrian geographic regions were represented in the data set and were assigned to the geographic regions of Austria, i.e., East, South, and West [33]. As suggested by Grange et al., we allocated type of occupation to three socio-professional categories (SPC), namely SPC+ (white-collar and freelance work), SPC - (manual work and domestic service), and retired/unemployed [11]. We categorized the highest attained education level as primary, secondary, and tertiary education.

We also collected self-reported information on general sunbed use (no/yes) by the question "In general, do you use sunbeds?" We assigned study participants who declared general sunbed use 
to the group of "recent sunbed users". The remaining participants were considered as "no recent sunbed users", as suggested by the literature [34]. The study questionnaire also assessed frequency of seasonal sunbed use, i.e., in winter (October to March) and summer (April to September). Given that fake tanning options providing a tanned appearance without UVR exposure are very popular, we asked for prevalent use of these sunless tanning products [35,36]. The according multiple-answer question "Do you usually use UV-free tanning products?" offered the possible choices self-tanning/bronzer lotions (e.g., dihydroxyacetone-based products), nutritional supplements (e.g., carotenoids), temporary bronzers, tanning accelerators/tan enhancers (e.g., tyrosine-based products), and also medical products (e.g., melanotan peptide hormones).

Participants classified their skin type (phototype I-VI) according to the Fitzpatrick scale [37]. We assessed occurrence of sunburn in the past year as well as personal and family skin cancer history (all: no/yes) [38]. Participants provided information on frequency of sun protection use from always $(=1)$ to never $(=5)$ by a five-point Likert scale. In addition, respondents rated their degree of agreement with motives to tan using a five-point Likert scale ranging from strongly agree $(=1)$ to strongly disagree $(=5)$. We summed the set of scores and calculated the mean of the respective items for generating the covariates sun protection and motives to tan. These covariates showed an internal consistency of Cronbach's alpha $=0.64$ and 0.73 , respectively, which we considered to be acceptable.

To assess sources of skin health information, participants were asked to indicate their familiarity with skin health information material published by healthcare providers, indoor tanning studios, and sunscreen producers [22,30]. A test of true-false questions measured participants' skin health knowledge. Summed amount of correct responses built the covariate knowledge score with higher scores indicating better knowledge.

We were further interested in self-reported lifestyle habits. We assessed information on current smoking status (non-smoking, ex-smoking, and smoking). Also, we collected data on regular outdoor sport activity (no/yes) and connectedness to nature ranging from none $(=0)$ to very high $(=10)$ as a measure for spending times outside and thus, recreational outdoor sun exposure [25]. We assessed sunbathing frequency and assigned participants to one of the two groups "no sun exposure" (0-5 days of sun exposure) and "sun exposure" ( $>5$ days of sun exposure) [27]. We also asked for information on duration of sun exposure (ranging from $<30 \mathrm{~min}$ to $>3 \mathrm{~h}$ ) and duration of sun exposure during midday hours (spanning from $<30 \mathrm{~min}$ to $>4 \mathrm{~h}$ ).

\subsection{Statistical Analysis}

Median splitting dichotomized variables to create low and high connectedness to nature, skin health knowledge, motives to tan, and sun protection. For the latter two variables, low $/$ high specifications were interpreted as more/less, respectively [25]. To compute prevalence estimates for sunbed use, we used the bootstrapping method based on 1000 bootstrap samples. We analyzed proportions, means, and standard deviation (SD) values of socio-demographic factors, skin health characteristics, attitudes, knowledge, and habits.

Group comparisons by each factor were done using chi²-tests, and two-sided level of significance was set at $\alpha=0.05$. Variables that statistically significantly differ in these group comparisons were further included as possible predictor variables for sunbed use in binary logistic regression analyses. We performed stepwise regression to keep the most relevant model according the AIC criterion. We conducted both crude and adjusted regression analysis and only reported odds ratio (OR) and $95 \%$ confidence intervals (95\% CI) of adjusted results. Nagelkerke's $\mathrm{R}^{2}$ and Hosmer-Lemeshow goodness-of-fit tests examined how well the regression model fitted the data set. All statistical analyses were performed using SPSS Version 21.0 (SPSS Inc., Chicago, IL, USA).

\section{Results}

In total, 1500 study subjects (50.5\% females, $18-74$ years, mean 44.7 , SD 15.4 years) participated in this questionnaire survey. Table 1 presents the overall distribution of seasonal prevalence of sunbed 
use during winter and summer months. As expected, sunbed use was statistically significantly more common and frequent during winter $(p<0.001)$.

Table 1. Seasonal one-year prevalence of sunbed use.

\begin{tabular}{lcccc}
\hline \multirow{2}{*}{ Sunbed use } & \multicolumn{4}{c}{ Season * } \\
\cline { 2 - 5 } & \multicolumn{2}{c}{ Winter } & \multicolumn{2}{c}{ Summer } \\
\cline { 2 - 5 } & $\mathbf{N}$ & $\%$ & $\mathbf{N}$ & $\%$ \\
\hline Overall & 1500 & 100.0 & 1500 & 100.0 \\
No recent sunbed use & 1366 & 91.1 & 1366 & 91.1 \\
Recent sunbed use & 134 & 8.9 & 134 & 8.9 \\
No seasonal sunbed use & 12 & 0.8 & 69 & 4.6 \\
Once a month & 45 & 3.0 & 23 & 1.5 \\
More than once a month & 45 & 3.0 & 27 & 1.8 \\
Once a week & 27 & 1.8 & 12 & 0.8 \\
More than once a week & 5 & 0.3 & 3 & 0.2 \\
\hline Notes: * Winter: October-March, summer: April-September.
\end{tabular}

Table 2 shows basic characteristics of the study population in relation to sunbed use. Overall one-year prevalence of sunbed use was $8.9 \%$ (95\% CI 7.5\%-10.4\%). We found a slightly higher prevalence in females $(9.2 \%, 95 \%$ CI $7.3 \%-11.2 \%)$ compared to males $(8.6 \%, 95 \%$ CI $6.7 \%-10.6 \%)$, but this gender difference did not reach statistical significance. Prevalences were highest in the youngest age group (18-29 years, $13.4 \%$ (95\% CI 9.5\%-17.7\%), with a statistically significant linear decrease with age: $30-39$ years: $11.9 \%(7.9 \%-15.8 \%), 40-49$ years: $9.1 \%(6.2 \%-12.4 \%), 50-59$ years: $7.3 \%(4.2 \%-10.8 \%)$, and $60-74$ years: $3.2 \%(1.3 \%-5.4 \%)$, respectively $(p<0.001)$. Also, participants living in the East of Austria were more likely to be among the group of sunbed users $(p<0.045)$.

Table 2. Socio-demographic characteristics of the study population, stratified by sunbed use.

\begin{tabular}{|c|c|c|c|c|c|c|}
\hline \multirow{2}{*}{ Factor } & \multirow{2}{*}{$\mathbf{N}$} & \multicolumn{2}{|c|}{ No Recent Sunbed Use } & \multicolumn{2}{|c|}{ Recent Sunbed Use } & \multirow{2}{*}{$\begin{array}{c}p \text {-Value } \\
\left(\mathrm{chi}^{2}\right)\end{array}$} \\
\hline & & $\mathbf{N}$ & $\%$ & $\mathbf{N}$ & $\%$ & \\
\hline \multicolumn{7}{|l|}{ Gender } \\
\hline Female & 758 & 688 & 90.8 & 70 & 9.2 & \\
\hline Male & 742 & 678 & 91.4 & 64 & 8.6 & 0.679 \\
\hline \multicolumn{7}{|l|}{ Age (years) } \\
\hline $18-29$ & 305 & 264 & 86.6 & 41 & 13.4 & \\
\hline $30-39$ & 278 & 245 & 88.1 & 33 & 11.9 & \\
\hline $40-49$ & 340 & 309 & 90.9 & 31 & 9.1 & \\
\hline $50-59$ & 260 & 241 & 92.7 & 19 & 7.3 & \\
\hline $60-74$ & 317 & 307 & 96.8 & 10 & 3.2 & $0.001 * *$ \\
\hline \multicolumn{7}{|c|}{ Geographic region in Austria } \\
\hline East & 644 & 573 & 89.0 & 71 & 11.0 & \\
\hline South & 320 & 298 & 93.1 & 22 & 6.9 & \\
\hline West & 536 & 495 & 92.4 & 41 & 7.6 & $0.045^{*}$ \\
\hline \multicolumn{7}{|l|}{ Place of residence } \\
\hline Rural & 1020 & 927 & 90.9 & 93 & 9.1 & \\
\hline Urban & 480 & 439 & 91.5 & 41 & 8.5 & 0.715 \\
\hline \multicolumn{7}{|l|}{ Education level } \\
\hline Primary & 357 & 329 & 92.2 & 28 & 7.8 & \\
\hline Secondary & 706 & 634 & 89.8 & 72 & 10.2 & \\
\hline Tertiary & 437 & 403 & 92.2 & 34 & 7.8 & 0.269 \\
\hline \multicolumn{7}{|c|}{ Socio-professional category (SPC) } \\
\hline SPC+ & 572 & 517 & 90.4 & 55 & 9.6 & \\
\hline $\mathrm{SPC}-$ & 475 & 429 & 90.3 & 46 & 9.7 & \\
\hline Retired/unemployed & 453 & 420 & 92.7 & 33 & 7.3 & 0.338 \\
\hline \multicolumn{7}{|l|}{ Personal status } \\
\hline Single & 507 & 456 & 89.9 & 51 & 10.1 & \\
\hline Partner & 993 & 910 & 91.6 & 83 & 8.4 & 0.275 \\
\hline
\end{tabular}


Table 3 shows prevalent sunbed use according to individual skin health characteristics and habits. Compared to non-users, sunbed users were more likely to smoke, have darker skin pigmentation (skin type III+), low connectedness to nature (all $p<0.05$ ), outdoor sun exposure, more motives to tan, and also use of UV-free tanning products (all $p<0.001$ ).

Table 3. Health behavior and skin health characteristics of the study samples, stratified by sunbed use.

\begin{tabular}{|c|c|c|c|c|c|c|}
\hline \multirow{2}{*}{ Factor } & \multirow{2}{*}{$\mathbf{N}$} & \multicolumn{2}{|c|}{ No Recent Sunbed Use } & \multicolumn{2}{|c|}{ Recent Sunbed Use } & \multirow{2}{*}{$\begin{array}{c}p \text {-Value } \\
\left(\mathrm{chi}^{2}\right)\end{array}$} \\
\hline & & $\mathbf{N}$ & $\%$ & $\mathbf{N}$ & $\%$ & \\
\hline \multicolumn{7}{|l|}{ Smoking } \\
\hline Non-smoking & 841 & 782 & 93.0 & 59 & 7.0 & \\
\hline Ex-smoking & 313 & 285 & 91.1 & 28 & 8.9 & \\
\hline Smoking & 346 & 299 & 86.4 & 47 & 13.6 & $0.002 *$ \\
\hline \multicolumn{7}{|l|}{ Skin type } \\
\hline I & 79 & 76 & 96.2 & 3 & 3.8 & \\
\hline II & 441 & 411 & 93.2 & 30 & 6.8 & \\
\hline III & 657 & 585 & 89.0 & 72 & 11.0 & \\
\hline IV-VI & 323 & 294 & 91.0 & 29 & 9.0 & $0.040 *$ \\
\hline \multicolumn{7}{|c|}{ Skin cancer history } \\
\hline \multicolumn{7}{|l|}{ Personal } \\
\hline Yes & 230 & 215 & 93.5 & 15 & 6.5 & \\
\hline No & 1270 & 1151 & 90.6 & 119 & 9.4 & 0.163 \\
\hline \multicolumn{7}{|l|}{ Family } \\
\hline Yes & 147 & 138 & 93.9 & 9 & 6.1 & \\
\hline No & 1353 & 1228 & 90.8 & 125 & 9.2 & 0.208 \\
\hline \multicolumn{7}{|l|}{ Sunburn } \\
\hline Yes & 461 & 410 & 88.9 & 51 & 11.1 & \\
\hline No & 1039 & 956 & 92.0 & 83 & 8.0 & 0.054 \\
\hline \multicolumn{7}{|l|}{ Sun exposure } \\
\hline Yes & 707 & 619 & 87.6 & 88 & 12.4 & \\
\hline No & 793 & 747 & 94.2 & 46 & 5.8 & $0.001^{* *}$ \\
\hline \multicolumn{7}{|l|}{ Sun protection } \\
\hline Low & 722 & 666 & 92.2 & 56 & 7.8 & \\
\hline High & 778 & 700 & 90.0 & 78 & 10.0 & 0.124 \\
\hline \multicolumn{7}{|l|}{ Motives to tan } \\
\hline Low & 732 & 638 & 87.2 & 94 & 12.8 & \\
\hline High & 768 & 728 & 94.8 & 40 & 5.2 & $0.001^{* *}$ \\
\hline \multicolumn{7}{|c|}{ Connectedness to nature } \\
\hline Low & 475 & 418 & 88.0 & 57 & 12.0 & \\
\hline High & 1025 & 948 & 92.5 & 77 & 7.5 & $0.005^{*}$ \\
\hline \multicolumn{7}{|c|}{ Skin health knowledge } \\
\hline Low & 319 & 290 & 90.9 & 29 & 9.1 & \\
\hline High & 1181 & 1076 & 91.1 & 105 & 8.9 & 0.911 \\
\hline \multicolumn{7}{|l|}{ Sport activity } \\
\hline Yes & 942 & 848 & 90.0 & 94 & 10.0 & \\
\hline No & 558 & 518 & 92.8 & 40 & 7.2 & 0.065 \\
\hline \multicolumn{7}{|l|}{ UV-free tanning } \\
\hline Yes & 159 & 134 & 84.3 & 25 & 15.7 & \\
\hline No & 1341 & 1232 & 91.9 & 109 & 8.1 & $0.001^{* *}$ \\
\hline
\end{tabular}

Item-based specifications showed that besides more consumption of UV-free tanning products in general, sunbed users also reported more use of temporary bronzers and tanning accelerators/tan enhancers (Table 4). However, non-recent sunbed users were more likely to consume nutritional supplements as endogenous tanning agents $(p<0.04)$. Furthermore, skin health information by healthcare providers was more often gathered among non-recent sunbed users $(p<0.012)$, whereas indoor tanning studios as information source was more common among users $(p<0.001)$. Knowledge on risk of sunbed use was higher among non-users $(p<0.001)$, while users were more 
aware of skin aging due to sun exposure $(p<0.028)$. Agreements with statements regarding motives to tan were consistently higher in the sunbed user group (all $p<0.05$ ), except for concerns about acne ( $p=$ n.s.). Regarding sun protection habits, sunbed users were less likely to seek shade and wear a hat or sun-protective garments (all $p<0.05$ ).

Table 4. Distribution of tanning attitudes, skin health knowledge, and sun protective habits, stratified by sunbed use.

\begin{tabular}{|c|c|c|c|c|c|c|}
\hline \multirow{2}{*}{ Factor } & \multirow{2}{*}{$\begin{array}{c}\text { Total } \\
\mathbf{N}\end{array}$} & \multicolumn{2}{|c|}{ No Recent Sunbed Use } & \multicolumn{2}{|c|}{ Recent Sunbed Use } & \multirow{2}{*}{$p$-Value $\left(\mathrm{chi}^{2}\right)$} \\
\hline & & $\mathbf{N}$ & $\%$ & $\mathbf{N}$ & $\%$ & \\
\hline \multicolumn{7}{|l|}{ UV-free tanning products } \\
\hline No use & 1341 & 1232 & 90.2 & 109 & 81.3 & $0.001 * *$ \\
\hline Self-tanning/bronzer lotions & 108 & 93 & 6.8 & 15 & 11.2 & 0.061 \\
\hline Nutritional supplements & 31 & 93 & 6.8 & 6 & 4.5 & $0.040 *$ \\
\hline Temporary bronzers & 24 & 25 & 1.8 & 6 & 4.5 & $0.005^{*}$ \\
\hline Tanning accelerator/tan enhancers & 13 & 18 & 1.3 & 5 & 3.7 & $0.001 * *$ \\
\hline Medical products & 4 & 8 & 0.6 & 1 & 0.7 & 0.259 \\
\hline \multicolumn{7}{|l|}{ Skin health information publisher } \\
\hline Healthcare providers & 1247 & 1146 & 83.9 & 101 & 75.4 & $0.012 *$ \\
\hline Indoor tanning studios & 160 & 96 & 7.0 & 64 & 47.8 & $0.001^{* *}$ \\
\hline Sunscreen producers & 804 & 725 & 53.1 & 79 & 59.0 & 0.193 \\
\hline \multicolumn{7}{|l|}{ Skin health knowledge } \\
\hline Risks of sunbed use & 1190 & 1105 & 80.9 & 85 & 63.4 & $0.001 * *$ \\
\hline Risks of sun exposure & 1187 & 1088 & 79.6 & 99 & 73.9 & 0.117 \\
\hline Skin aging risk of sun exposure & 1281 & 1158 & 84.8 & 123 & 91.8 & $0.028 *$ \\
\hline Sunburn risk for tanned skin & 1260 & 1141 & 83.5 & 119 & 88.8 & 0.112 \\
\hline \multicolumn{7}{|l|}{ Motives to tan: When I am tanned ... } \\
\hline I have more sex appeal. & 1069 & 955 & 69.9 & 114 & 85.1 & $0.001 * *$ \\
\hline I am more attractive. & 679 & 584 & 42.8 & 95 & 70.9 & $0.001 * *$ \\
\hline I am more self-confident. & 405 & 347 & 25.4 & 58 & 43.3 & $0.001^{* *}$ \\
\hline I am not so pale. & 796 & 690 & 50.5 & 106 & 79.1 & $0.001 * *$ \\
\hline I am less concerned about acne. & 333 & 296 & 21.7 & 37 & 27.6 & 0.114 \\
\hline I am less concerned about stretch marks. & 248 & 214 & 15.7 & 34 & 25.4 & $0.004^{*}$ \\
\hline I look slimmer. & 644 & 572 & 41.9 & 72 & 53.7 & $0.008 *$ \\
\hline I look fitter. & 298 & 262 & 19.2 & 36 & 26.9 & $0.033 *$ \\
\hline \multicolumn{7}{|l|}{ Sun protection: For sun protection ... } \\
\hline I use sunscreen (min. SPF 15). & 996 & 907 & 66.4 & 89 & 66.4 & 0.996 \\
\hline I seek shade. & 1219 & 1129 & 82.7 & 90 & 67.2 & $0.001 * *$ \\
\hline I wear a hat. & 732 & 681 & 49.9 & 51 & 38.1 & $0.009 *$ \\
\hline I wear sunglasses. & 1136 & 1033 & 75.6 & 103 & 76.9 & 0.749 \\
\hline I wear sun-protective garments. & 793 & 737 & 54.0 & 56 & 41.8 & 0.007 * \\
\hline I avoid midday sun. & 878 & 810 & 59.3 & 68 & 50.7 & 0.055 \\
\hline
\end{tabular}

Table 5 depicts the results of the adjusted binary regression model (Hosmer-Lemeshow-Test: $\left.\mathrm{chi}^{2}=2.965, p=0.937\right)$. Nagelkerke's $\mathrm{R}^{2}$ suggested that the model explains $13 \%$ of the variation in the outcome and that the model was a good fit to the data $(p>0.05)$. The overall model predictive ability was about $91 \%$. Factors predicting sunbed use were age, by trend decreasing with older age (for 60-74 year olds: OR $=0.30,95 \%$ CI $0.14-0.62, p<0.001$ ), place of living by geographic regions of Austria (East vs. South, OR $=1.58,95 \%$ CI 1.04-2.41, $p<0.032$ ), smoking (non-smoking vs. current smoking, OR $=1.87,95 \%$ CI 1.22-2.87, $p<0.004$ ), skin type (skin type I $v$ s. darker skin, by trend increasing with darker skin, $p<0.026)$, more sun exposure ( $\mathrm{OR}=1.69,95 \%$ CI 1.13-2.51, $p<0.01)$, more motives to $\tan (\mathrm{OR}=2.10,95 \% \mathrm{CI} 1.40-3.15, p<0.001)$, use of UV-free tanning products $(\mathrm{OR}=1.82$, $95 \%$ CI 1.11-2.98, $p<0.018)$. 
Table 5. Results of the linear regression analysis on sunbed use.

\begin{tabular}{|c|c|c|c|}
\hline Factor & OR & $95 \% \mathrm{CI}$ & $p$-Value \\
\hline \multicolumn{4}{|l|}{ Age } \\
\hline $18-29$ & 1 & - & 0.014 * \\
\hline $30-39$ & 1.02 & $0.61-1.72$ & 0.934 \\
\hline $40-49$ & 0.84 & $0.49-1.41$ & 0.504 \\
\hline $50-59$ & 0.68 & $0.37-1.24$ & 0.207 \\
\hline $60-74$ & 0.30 & $0.14-0.62$ & $0.001^{* *}$ \\
\hline \multicolumn{4}{|c|}{ Geographic regions of Austria } \\
\hline East & 1 & - & 0.040 * \\
\hline South & 1.58 & $1.04-2.41$ & $0.032 *$ \\
\hline West & 0.95 & $0.54-1.65$ & 0.845 \\
\hline \multicolumn{4}{|l|}{ Smoking } \\
\hline Non-smoking & 1 & - & 0.014 * \\
\hline Ex-smoking & 1.44 & $0.88-2.35$ & 0.149 \\
\hline Smoking & 1.87 & $1.22-2.87$ & 0.004 * \\
\hline \multicolumn{4}{|l|}{ Skin type } \\
\hline I & 1 & - & $0.026^{*}$ \\
\hline II & 1.35 & $0.39-4.63$ & 0.635 \\
\hline III & 2.58 & $0.78-8.57$ & 0.123 \\
\hline IV-VI & 1.89 & $0.54-6.55$ & 0.317 \\
\hline Sun exposure & 1.69 & $1.13-2.51$ & 0.010 * \\
\hline Motives to tan & 2.10 & $1.40-3.15$ & $0.001^{* *}$ \\
\hline Connectedness to nature & 1.39 & $0.94-2.03$ & 0.096 \\
\hline UV-free tanning & 1.82 & $1.11-2.98$ & $0.018 *$ \\
\hline
\end{tabular}

\section{Discussion}

So far, little is known on potential lifestyle-associated explanations for rising skin cancer incidence and mortality rates in Austria. A considerable amount of studies have investigated prevalence of sunbed use, characteristics, attitudes, and knowledge of sunbed users in other European countries $[8,11,21,34,39]$. To close this knowledge gap, the present population-based study assessed prevalent general and seasonal sunbed use as well as skin health knowledge, attitudes, and habits among Austrian citizens. The practical and theoretical implications of these findings are discussed from a Public (Skin) Health perspective.

In a recently published meta-analysis including U.S., European, and Australian studies, prevalence of past-year sunbed use was $14 \%$ for adults, $18 \%$ for adolescents, and as high as $43 \%$ for university students [13]. In our sample, past-year sunbed use prevalence was $9 \%$ in general and $13 \%$ among the youngest age group (18-29 years). However, varying prevalence rates of ever sunbed use were reported across Europe. Schneider et al. identified as many as $47 \%$ ever and $21 \%$ current users among German adults [40]. These rates were higher compared to French data, where $13 \%$ of the general population reported having tanned indoors at least once in their lifetime and $4 \%$ in the past year, with higher rates $(10 \%)$ among the younger population (20-25 years) [39].

To assess predictors of sunbed use, we employed an adjusted regression model showing both an adequate goodness-of-fit to the data and strong predictive power. Sunbed users were typically younger, lived in the Eastern region of Austria, smoked cigarettes, used UV-free tanning products, and reported darker skin, outdoor sun exposure, and more motives to tan. These socio-economic profiles of recent sunbed users have not been addressed in national skin health awareness campaigns 
in Austria so far. Approaches sensitive to recipients' socio-economic background and educational level might more successfully increase general skin cancer risk awareness and also reduce sunbed use.

Sunbed exposure is a risk factor for melanoma even among persons who never experienced sunburns from indoor or outdoor UVR contact [41]. Although a tan does not protect against sunburn, individuals often tan indoors before planned sun exposure, presumably to prevent sunburns [10]. Alternatively, a wide range of UV-free tanning products are commercially available and commonly used to boost the tanning process. Their consumption is associated with more frequent use and higher risk for tanning addiction [36].

We found a respective prevalence of about $11 \%$ and statistically significant higher use of UV-free tanning products among sunbed users compared to non-users. Also, their self-reported consumption predicted sunbed use in our regression model. To our knowledge, this is the first study evaluating the prevailing use of these products among Austrian citizens. This finding is of relevance for skin health counseling and could be further integrated in future implementation of labeling requirements for these products, e.g., showing skin health messages. Day et al. differentiated between three distinct types of tanning behavior: outdoor tanners, fake tanners, and tan avoiders [35]. This differentiation was beyond the scope of our study, as we aimed at providing so far lacking baseline data on recreational skin health behavior among the Austrian population. However, evaluating personal tanning preferences and their interaction with long-term skin health outcomes may reveal novel Public (Skin) Health strategies.

Recently, we reported on geographic differences in melanoma incidence and mortality trends in Austria [29]. In addition to this, the current analysis revealed that prevalence of sunbed use among Austria citizens followed an East-West gradient. This regional gradient has already been shown for various lifestyle-associated health determinants such as cardiovascular diseases, diabetes mellitus, and obesity [42]. Urban-rural influences on socio-economic status and recreational habits might explain this well-established association. However, a South-North gradient with higher prevalence of sunbed exposure in the North compared to the South was found in several European countries [34,43]. This so far unknown result on geographical associations with sun exposure habits in Austria could motivate future hypothesis-driven evaluations to identify novel strategies and risk groups for targeted awareness campaigns.

Ezzedine et al. found a correlation between indoor and outdoor UVR exposure habits and lifestyle habits [34]. In agreement with Grange et al., our analysis showed that sunbed users were less likely to use sun-protective measures such as hats or clothes than non-users [11]. Further, we observed higher sunbed use prevalence in younger study subjects. Accordingly, several publications identified the typical sunbed user as being female, of younger age and-beyond this-having a higher socio-professional category and a fairer phototype $[11,34,40,43,44]$. Nevertheless, Schneider et al. found higher prevalence rates among individuals with medium education, whereas age, partnership status, and nationality were not associated with sunbed use [40]. Exposure to artificial UVR increases the risk of skin cancer, irrespective of age of initial indoor tanning [7,45]. Boniol and colleagues reported that melanoma risk was higher if first exposure to indoor tanning equipment occurred before the age of 35 years [8]. Initiation of sunbed use at young adult age suggests the need for targeted interventions. In particular, adolescents should be made aware of the long-term skin health risks of sunbed use when used for short-term cosmetic tanning purposes [15].

Our analysis also found that sunbed use was associated with smoking habits and outdoor sun exposure. This is in line with vast scientific evidence, showing that sunbed use is correlated with risky lifestyle habits including smoking cigarettes, drinking alcohol, eating unhealthy food, and sunbathing and thus, accumulating risk factors for skin health $[11,34,40,44,46]$. In this context, Gunn et al. verified that smoking and sunbed use are strongly associated with photoaging and wrinkling in both genders, while a reasonable lifestyle preserves youthful looks on the long run [47].

Appearance- and emotion-based motives to tan influence both solar and indoor tanning habits [48]. Although sunbed users were shown to know that sun exposure reduces the skin's regenerative capacity, they consider that a tan makes a person look more attractive and protects the skin $[11,34]$. In our survey, 
sunbed users compared to non-users were more aware of the risk of photo-induced skin aging, but they perceived a lower skin health risk in connection with sunbed use. Likewise, agreements with statements regarding motives to tan were consistently higher in the sunbed user group. This observation suggests that research entangling motives of indoor tanners could provide valuable input for larger-scale skin cancer prevention policies and monitoring programs [7].

Knowledge, attitudes, and intentions of individuals are vital targets for public education programs. However, there is still a lack of information among consumers regarding the safety of sunbeds use [46]. Schneider et al. reported alarmingly poor quality of services provided by tanning parlors [40]. In our study, non-recent sunbed users more often received skin health information by healthcare providers, whereas users more often mentioned indoor tanning studios as a source of information. Given the known publishing source bias of information material, these finding suggests the need for standardizing the content of skin health educative information [23].

Sunbed users experience positive emotions and relaxation during frequent and intentional exposure to artificial UVR, potentially leading to tanning addiction, also referred to as tanorexia [49]. This concept of tanorexia is supported by the observation that the annual exposure remained constant over time among German sunbed users [21]. Contrarily, Guy et al. reported a recent decrease in sunbed use among U.S. adults [20]. This decline might reflect increased public awareness of the carcinogenic potential sunbed use due to respective skin health campaigns and implementation of laws restricting sunbed access among minors $[14,16]$. Characteristics associated with sunbed use cessation include greater awareness of skin cancer risk and higher educational level [21]. Evidence suggests that positive attitudes towards tanning are a key barrier to adopt measures towards preventing skin health hazards [21,48]. In addition to tackling these pro-tanning societal framing and motives to tan, awareness campaigns focusing on sunbed use cessation should also account for gender-and age-specific requirements.

Besides the aforementioned Public (Skin) Health aspects of sunbed use, there is evidence of detrimental risks of UVR exposure avoidance contributing to a higher risk for all-cause mortality $[50,51]$. These photo-induced benefits are probably due to the still controversially discussed Vitamin D-associated health effects [52,53]. Nevertheless, according to Woo et al., Vitamin D supplementation is a feasible means for adequate Vitamin D supply while avoiding sunbed exposure as a the risk factor for skin cancer and skin aging [54].

The present survey is the first empirical study that collected data from a large, community-based sample representing the Austrian census data [26]. Amount of participants $(n=1500)$ was equal to comparable European studies such as the French EDIFICE Melanoma survey $(n=1502)$, although France has a far larger population size [11,55]. Public (Skin) Health research has wide implications for clinical practice and community skin health promotion. Closing the knowledge gap regarding sunbed use in Austria, the current study theoretically advances the understanding of prevailing skin health habits in the general Austrian population.

However, the findings of this study are subject to several limitations, mainly related to the cross-sectional design. Thus, the survey data do not allow for causal relations of individual characteristics and indoor tanning behaviors. We used stratified random sampling on the basis of the official national telephone directory list to ensure representativeness of the study population. However, as in every telephone-based survey, potential study participants needed to have a valid telephone number when contacted, thus introducing selection bias and limiting generalizability of the study results to the general adult population. Also, we assessed self-reported data, which might be subject to non-response, reporting, and recall bias. Nevertheless, recall bias regarding UVR exposure seems to be small and self-reported data on phenotypic characteristics, sunburn history, and sun protection behavior were shown to be reproducible [56,57]. We assume that these data represent a trustworthy picture of actual skin health habits executed by the Austrian population. Although our data on recent sunbed users were based on the respective group of only about $9 \%$ of study participants, they were comparable with sunbed use prevalence reported in other studies, e.g., Grange et al. [11]. 
Thus, we also used the bootstrapping method based on 1000 bootstrap samples to additionally provide prevalence estimates for sunbed use in Austria. The herein presented data may serve as a baseline for tracking progress achieved by future Public (Skin) Health campaigns, as suggested by Davis et al. [58]. Since September 2010, Austria has implemented a legislation to ban indoor tanning bed use for minors nationwide [59]. Further research could analyze the impact of this ban on skin health-related longitudinal trends and behavior changes in the general population.

\section{Conclusions}

The current research extends the understanding of prevailing recreational skin health habits by adding hitherto lacking data on sunbed use prevalence in the general Austrian population. Sunbed users were typically young, smoke cigarettes, use UV-free tanning products, and sunbathe outdoors. Also, prevalence of sunbed use in Austria followed an East-West gradient. National skin health awareness campaigns have not yet address these at-risk profiles for sunbed use. From a Public (Skin) Health perspective, approaches sensitive to recipients' socio-economic background and educational level might more successfully increase general skin cancer risk awareness and also reduce sunbed use.

Acknowledgments: This research work was partly funded by the Austrian Climate and Energy Fund, Project "UVSkinRisk-Health at risk through UV induced Skin Cancer in the Context of a Changing Climate".

Author Contributions: Daniela Haluza conceived the idea for the manuscript and prepared the draft of the manuscript. Stana Simic and Hanns Moshammer supervised the study conceptualization and design, provided strategy for data analyses and interpretation, and collaborated to manuscript writing.

Conflicts of Interest: The authors declare no conflict of interest.

\section{References}

1. Jablonski, N.G. Human skin pigmentation as an example of adaptive evolution. P. Am. Philos. Soc. 2012, $156,45-57$.

2. Pludowski, P.; Holick, M.F.; Pilz, S.; Wagner, C.L.; Hollis, B.W.; Grant, W.B.; Shoenfeld, Y.; Lerchbaum, E.; Llewellyn, D.J.; Kienreich, K.; et al. Vitamin D effects on musculoskeletal health, immunity, autoimmunity, cardiovascular disease, cancer, fertility, pregnancy, dementia and mortality-A review of recent evidence. Autoimmun. Rev. 2013, 12, 976-989. [CrossRef] [PubMed]

3. Cui, R.; Widlund, H.R.; Feige, E.; Lin, J.Y.; Wilensky, D.L.; Igras, V.E.; D'Orazio, J.; Fung, C.Y.; Schanbacher, C.F.; Granter, S.R.; et al. Central role of p53 in the suntan response and pathologic hyperpigmentation. Cell 2007, 128, 853-864. [CrossRef] [PubMed]

4. Nielsen, K.; Masback, A.; Olsson, H.; Ingvar, C. A prospective, population-based study of 40,000 women regarding host factors, $\mathrm{UV}$ exposure and sunbed use in relation to risk and anatomic site of cutaneous melanoma. Int. J. Cancer 2012, 131, 706-715. [CrossRef] [PubMed]

5. Lim, H.W.; James, W.D.; Rigel, D.S.; Maloney, M.E.; Spencer, J.M.; Bhushan, R. Adverse effects of ultraviolet radiation from the use of indoor tanning equipment: Time to ban the tan. J. Am. Acad. Dermatol. 2011, 64, 893-902. [CrossRef] [PubMed]

6. Wehner, M.R.; Shive, M.L.; Chren, M.M.; Han, J.; Qureshi, A.A.; Linos, E. Indoor tanning and non-melanoma skin cancer: Systematic review and meta-analysis. BMJ 2012, 345, e5909. [CrossRef] [PubMed]

7. Colantonio, S.; Bracken, M.B.; Beecker, J. The association of indoor tanning and melanoma in adults: Systematic review and meta-analysis. J. Am. Acad. Dermatol. 2014, 70, 847-857. [CrossRef] [PubMed]

8. Boniol, M.; Autier, P.; Boyle, P.; Gandini, S. Cutaneous melanoma attributable to sunbed use: Systematic review and meta-analysis. BMJ 2012, 345, e4757. [CrossRef] [PubMed]

9. O'Sullivan, N.A.; Tait, C.P. Tanning bed and nail lamp use and the risk of cutaneous malignancy: A review of the literature. Australas. J. Dermatol. 2014, 55, 99-106. [CrossRef] [PubMed]

10. Dennis, L.K.; Lowe, J.B. Does artificial UV use prior to spring break protect students from sunburns during spring break? Photodermatol. Photoimmunol. Photomed. 2013, 29, 140-148. [CrossRef] [PubMed]

11. Grange, F.; Mortier, L.; Crine, A.; Robert, C.; Sassolas, B.; Lebbe, C.; Lhomel, C.; Saiag, P. Prevalence of sunbed use, and characteristics and knowledge of sunbed users: Results from the French population-based edifice melanoma survey. J. Eur. Acad. Dermatol. Venereol. 2015, 29 (Suppl. 2), 23-30. [CrossRef] [PubMed] 
12. Borner, F.U.; Schutz, H.; Wiedemann, P. A population-based survey on tanning bed use in germany. BMC Dermatol. 2009, 9, 6. [CrossRef] [PubMed]

13. Wehner, M.R.; Chren, M.M.; Nameth, D.; Choudhry, A.; Gaskins, M.; Nead, K.T.; Boscardin, W.J.; Linos, E. International prevalence of indoor tanning a systematic review and meta-analysis. JAMA Dermatol. 2014, 150, 390-400. [CrossRef] [PubMed]

14. Obayan, B.; Geller, A.C.; Resnick, E.A.; Demierre, M.F. Enacting legislation to restrict youth access to tanning beds: A survey of advocates and sponsoring legislators. J. Am. Acad. Dermatol. 2010, 63, 63-70. [CrossRef] [PubMed]

15. Pawlak, M.T.; Bui, M.; Amir, M.; Burkhardt, D.L.; Chen, A.K.; Dellavalle, R.P. Legislation restricting access to indoor tanning throughout the world. Arch. Dermatol. 2012, 148, 1006-1012. [CrossRef] [PubMed]

16. Hirst, N.; Gordon, L.; Gies, P.; Green, A.C. Estimation of avoidable skin cancers and cost-savings to government associated with regulation of the solarium industry in Australia. Health Policy 2009, 89, 303-311. [CrossRef] [PubMed]

17. Guy, J.G.P.; Thomas, C.C.; Thompson, T.; Watson, M.; Massetti, G.M.; Richardson, L.C. Vital signs: Melanoma incidence and mortality trends and projections-United States, 1982-2030. MMWR Morb. Mortal. Wkly. Rep. 2015, 64, 591-596. [PubMed]

18. Perez, D.; Kite, J.; Dunlop, S.M.; Cust, A.E.; Goumas, C.; Cotter, T.; Walsberger, S.C.; Dessaix, A.; Bauman, A. Exposure to the "dark side of tanning" skin cancer prevention mass media campaign and its association with tanning attitudes in new south wales, Australia. Health Educ. Res. 2015, 30, 336-346. [CrossRef] [PubMed]

19. Barysch, M.J.; Cozzio, A.; Kolm, I.; Hrdlicka, S.R.; Brand, C.; Hunger, R.; Kreyden, O.; Schaffner, R.; Zaugg, T.; Dummer, R. Internet based health promotion campaign against skin cancer-Results of www.skincheck.ch in switzerland. Eur. J. Dermatol. 2010, 20, 109-114. [PubMed]

20. Guy, G.P.J.; Berkowitz, Z.; Holman, D.M.; Hartman, A.M. Recent changes in the prevalence of and factors associated with frequency of indoor tanning among US adults. JAMA Dermatol. 2015, 151, 1256-1259. [CrossRef] [PubMed]

21. Bock, C.; Diehl, K.; Litaker, D.; Breitbart, E.W.; Greinert, R.; Schneider, S. Sunbed use in germany: Trends, user histories and factors associated with cessation and readiness to change. Br. J. Dermatol. 2013, 169, 441-449. [CrossRef] [PubMed]

22. Haluza, D.; Cervinka, R. Perceived relevance of educative information on public (skin) health: A cross-sectional questionnaire survey. J. Prev. Med. Public Health 2013, 46, 82-88. [CrossRef] [PubMed]

23. Haluza, D.; Cervinka, R. Public (skin) health and the publishing source bias of Austrian information material. Cent. Eur. J. Med. 2014, 9, 169-176. [CrossRef]

24. Haluza, D.; Moshammer, H.; Kundi, M.; Cervinka, R. Public (skin) health perspectives of gender differences in tanning habits and sun protective behaviour: A cross-sectional questionnaire survey. Wien. Klin. Wochenschr. 2015, 127, 124-131. [CrossRef] [PubMed]

25. Haluza, D.; Simic, S.; Höltge, J.; Cervinka, R.; Moshammer, H. Connectedness to nature and public (skin) health perspectives: Results of a representative, population-based survey among Austrian residents. Int. J. Environ. Res. Public Health 2014, 11, 1176-1191. [CrossRef] [PubMed]

26. Haluza, D.; Simic, S.; Höltge, J.; Cervinka, R.; Moshammer, H. Gender aspects of recreational sun-protective behavior: Results of a representative, population-based survey among Austrian residents. Photodermatol. Photoimmunol. Photomed. 2016, 32, 11-21. [CrossRef] [PubMed]

27. Haluza, D.; Simic, S.; Moshammer, H. Sun exposure prevalence and associated skin health habits: Results from the Austrian population-based UVSkinRisk survey. Int. J. Environ. Res. Public Health 2016, 13, 141. [CrossRef] [PubMed]

28. Statistik Austria. Melanoma Incidence and Mortality in Austria in 2012. Available online: http:/ / www.statistik. at/ web_de/ statistiken/ menschen_und_gesellschaft/gesundheit/ krebserkrankungen/haut/index.html (accessed on 26 January 2016).

29. Haluza, D.; Simic, S.; Moshammer, H. Temporal and spatial melanoma trends in Austria: An ecological study. Int. J. Environ. Res. Public Health 2014, 11, 734-748. [CrossRef] [PubMed]

30. Haluza, D.; Schwab, M.; Simic, S.; Cervinka, R.; Moshammer, H. Perceived relevance of educative information on public (skin) health: Results of a representative, population-based telephone survey. Int. J. Environ. Res. Public Health 2015, 12, 14260-14274. [CrossRef] [PubMed] 
31. Purdie, D.M.; Dunne, M.P.; Boyle, F.M.; Cook, M.D.; Najman, J.M. Health and demographic characteristics of respondents in an australian national sexuality survey: Comparison with population norms. J. Epidemiol. Commun. Health 2002, 56, 748-753. [CrossRef]

32. Statistik Austria. Register-Based Census Held on 31 October 2011. Available online: http://www.statistik.at/ web_en/statistics/PeopleSociety/population/population_censuses_register_based_census_register_based_ labour_market_statistics/totaL_population/index.html (accessed on 26 January 2016).

33. Statistik Austria. Nomenclature of territorial units for statistics (NUTS) Austria 2014. Available online: http://www.statistik.at/web_en/classifications/regional_breakdown/nuts_units/033784.html (accessed on 26 January 2016).

34. Ezzedine, K.; Malvy, D.; Mauger, E.; Nageotte, O.; Galan, P.; Hercberg, S.; Guinot, C. Artificial and natural ultraviolet radiation exposure: Beliefs and behaviour of 7200 French adults. J. Eur. Acad. Dermatol. Venereol. 2008, 22, 186-194. [CrossRef] [PubMed]

35. Day, A.K.; Oxlad, M.; Roberts, R.M. Predictors of sun-related behaviors among young women: Comparisons between outdoor tanners, fake tanners, and tan avoiders. J. Am. Coll. Health 2013, 61, 315-322. [CrossRef] [PubMed]

36. Herrmann, J.L.; Cunningham, R.; Cantor, A.; Elewski, B.E.; Elmets, C.A. Tanning accelerators: Prevalence, predictors of use, and adverse effects. J. Am. Acad. Dermatol. 2015, 72, 99-104. [CrossRef] [PubMed]

37. Fitzpatrick, T.B. The validity and practicality of sun-reactive skin types I through VI. Arch. Dermatol. 1988, 124, 869-871. [CrossRef] [PubMed]

38. Lykins, E.L.B.; Graue, L.O.; Brechting, E.H.; Roach, A.R.; Gochett, C.G.; Andrykowski, M.A. Beliefs about cancer causation and prevention as a function of personal and family history of cancer: A national, population-based study. Psychooncology 2008, 17, 967-974. [CrossRef] [PubMed]

39. Benmarhnia, T.; Leon, C.; Beck, F. Exposure to indoor tanning in France: A population based study. BMC Dermatol. 2013, 13, 6. [CrossRef] [PubMed]

40. Schneider, S.; Zimmermann, S.; Diehl, K.; Breitbart, E.W.; Greinert, R. Sunbed use in German adults: Risk awareness does not correlate with behaviour. Acta. Derm. Venereol. 2009, 89, 470-475. [CrossRef] [PubMed]

41. Vogel, R.I.; Ahmed, R.L.; Nelson, H.H.; Berwick, M.; Weinstock, M.A.; Lazovich, D. Exposure to indoor tanning without burning and melanoma risk by sunburn history. J. Natl. Cancer Inst. 2014, 106, 6. [CrossRef] [PubMed]

42. Großschädl, F.; Stronegger, W.J. Regional trends in obesity and overweight among Austrian adults between 1973 and 2007. Wien. Klin. Wochenschr. 2012, 124, 363-369. [CrossRef] [PubMed]

43. Bataille, V.; Boniol, M.; De Vries, E.; Severi, G.; Brandberg, Y.; Sasieni, P.; Cuzick, J.; Eggermont, A.; Ringborg, U.; Grivegnée, A.-R.; et al. A multicentre epidemiological study on sunbed use and cutaneous melanoma in Europe. Eur. J. Cancer 2005, 41, 2141-2149. [CrossRef] [PubMed]

44. Veierod, M.B.; Couto, E.; Lund, E.; Adami, H.O.; Weiderpass, E. Host characteristics, sun exposure, indoor tanning and risk of squamous cell carcinoma of the skin. Int. J. Cancer 2014, 135, 413-422. [CrossRef] [PubMed]

45. Lazovich, D.; Vogel, R.I.; Berwick, M.; Weinstock, M.A.; Anderson, K.E.; Warshaw, E.M. Indoor tanning and risk of melanoma: A case-control study in a highly exposed population. Cancer Epidemiol. Biomarkers Prev. 2010, 19, 1557-1568. [CrossRef] [PubMed]

46. Schneider, S.; Krämer, H. Who uses sunbeds? A systematic literature review of risk groups in developed countries. J. Eur. Acad. Dermatol. Venereol. 2010, 24, 639-648. [CrossRef] [PubMed]

47. Gunn, D.A.; Dick, J.L.; van Heemst, D.; Griffiths, C.E.; Tomlin, C.C.; Murray, P.G.; Griffiths, T.W.; Ogden, S.; Mayes, A.E.; Westendorp, R.G.; et al. Lifestyle and youthful looks. Br. J. Dermatol. 2015, 172, 1338-1345. [CrossRef] [PubMed]

48. Joel Hillhouse, G.C.; Thompson, J.K.; Jacobsen, P.B.; Hillhouse, J. Investigating the role of appearance-based factors in predicting sunbathing and tanning salon use. J. Behav. Med. 2009, 32, 532-544. [PubMed]

49. Fisher, D.E.; James, W.D. Indoor tanning-Science, behavior, and policy. N. Engl. J. Med. 2010, 363, $901-903$. [CrossRef] [PubMed]

50. Lindqvist, P.G.; Epstein, E.; Landin-Olsson, M.; Ingvar, C.; Nielsen, K.; Stenbeck, M.; Olsson, H. Avoidance of sun exposure is a risk factor for all-cause mortality: Results from the melanoma in southern Sweden cohort. J. Intern. Med. 2014, 276, 77-86. [CrossRef] [PubMed]

51. Gallagher, R.P.; Lee, T.K.; Bajdik, C.D.; Borugian, M. Ultraviolet radiation. Chronic Dis. Can. 2010, 1, 51-68. 
52. Mason, R.S.; Reichrath, J. Sunlight vitamin d and skin cancer. Anticancer Agents Med. Chem. 2013, $13,83-97$. [CrossRef] [PubMed]

53. Holick, M.F. Sunlight and vitamin d for bone health and prevention of autoimmune diseases, cancers, and cardiovascular disease. Am. J. Clin. Nutr. 2004, 80, 1678S-1688S. [PubMed]

54. Woo, D.K.; Eide, M.J. Tanning beds, skin cancer, and vitamin d: An examination of the scientific evidence and public health implications. Dermatol. Ther. 2010, 23, 61-71. [CrossRef] [PubMed]

55. Sassolas, B.; Grange, F.; Touboul, C.; Lebbe, C.; Saiag, P.; Mortier, L.; Lhomel, C.; Robert, C. Sun exposure profile in the French population: Results of the EDIFICE melanoma survey. J. Eur. Acad. Dermatol. Venereol. 2015, 2, 6-10. [CrossRef] [PubMed]

56. Parr, C.L.; Hjartaker, A.; Laake, P.; Lund, E.; Veierod, M.B. Recall bias in melanoma risk factors and measurement error effects: A nested case-control study within the Norwegian women and cancer study. Am. J. Epidemiol. 2009, 169, 257-266. [CrossRef] [PubMed]

57. De Waal, A.C.; van Rossum, M.M.; Kiemeney, L.A.L.M.; Aben, K.K.H. Reproducibility of self-reported melanoma risk factors in melanoma patients. Melanoma. Res. 2014, 24, 592-601. [CrossRef] [PubMed]

58. Davis, K.J.; Cokkinides, V.E.; Weinstock, M.A.; O'Connell, M.C.; Wingo, P.A. Summer sunburn and sun exposure among US youths ages 11 to 18: National prevalence and associated factors. Pediatrics 2002, 110, 27-35. [CrossRef] [PubMed]

59. Bundesgesetzblatt: Für Die Republik Österreich. Available online: https:/ /www.ris.bka.gv.at/Dokumente/ BgblAuth/BGBLA_2010_II_106/BGBLA_2010_II_106.html (accessed on 26 January 2016).

(C) 2016 by the authors; licensee MDPI, Basel, Switzerland. This article is an open access article distributed under the terms and conditions of the Creative Commons by Attribution (CC-BY) license (http:/ / creativecommons.org/licenses/by/4.0/). 